\title{
Escrita acadêmica e organização retórica da introdução de artigos científicos em duas áreas disciplinares
}

\author{
Benedito Gomes Bezerra* \\ Iraci Nobre da Silva** \\ Amanda Cavalcante de Oliveira Lêdo ${ }^{* * *}$
}

Resumo: A introdução do artigo científico é uma seção estratégica destinada a contextualizar/situar o texto, implicitamente argumentando a favor da leitura do trabalho integral. Neste estudo, nosso objetivo é analisar a organização retórica de introduções de artigos escritos por graduandos de Letras e de Matemática, a fim de identificar as estratégias mobilizadas na escrita dos textos. Fundamentados em uma perspectiva sociorretórica, analisamos um corpus de 10 artigos, cujas introduções são examinadas com base no Modelo CARS (SWALES, 1990). Os resultados confirmam a mobilização de estratégias retóricas previstas pelo modelo. No entanto, cada área disciplinar utiliza, adicionalmente, estratégias retóricas peculiares.

Palavras-chave: Gêneros acadêmicos. Modelo CARS. Artigo científico.

\begin{abstract}
The introduction of the research article is a strategic section designed to contextualize/situate the text, arguing implicitly in favor of reading the full paper. In this study, our aim is to analyze the rhetorical organization of articles' introductions written by undergraduates in Language and Mathematics, in order to identify the strategies that are mobilized in the writing of the texts. Based on a socio-rhetorical perspective, we analyzed a corpus of ten articles, whose introductions are examined based on the CARS Model (SWALES, 1990). The results confirm the mobilization of rhetorical strategies indicated by the model. However, each disciplinary area additionally uses peculiar rhetorical strategies.
\end{abstract}

Keywords: Academic genres. CARS Model. Research article.

\footnotetext{
* Professor da Universidade de Pernambuco, Campus Mata Norte, e da Universidade Católica de Pernambuco. http://orcid.org/oooo-0oo2-7382-0937 / beneditobezerra@gmail.com

${ }^{* *}$ Professora da Universidade Estadual de Alagoas (UNEAL); doutoranda do Programa de Pós-Graduação em Ciências da Linguagem da Universidade Católica de Pernambuco (UNICAP). http://orcid.org/oooo0003-0029-1859 / penedoiraci@yahoo.com.br

${ }_{* * *}^{*}$ Professora da Universidade de Pernambuco (UPE), Campus Mata Norte. http://orcid.org/oooo-0ooz7178-9796 / amanda.ledo@upe.br
}



Este artigo está licenciado sob forma de uma licença Creative Commons Atribuição 4.0 Internacional, que permite uso irrestrito, distribuição e reprodução em qualquer meio, desde que a publicação original seja corretamente citada. 
Resumen: La introducción del artículo científico es una sección estratégica diseñada para contextualizar/situar el texto, argumentando implícitamente a favor de leer el artículo completo. En este estudio, nuestro objetivo es analizar la organización retórica de introducciones de artículos escritos por estudiantes universitarios de Letras y Matemática, con el fin de identificar las estrategias utilizadas en la redacción de textos. Basado en una perspectiva socio-retórica, analizamos un corpus de diez artículos, cuyas introducciones se examinan en base al Modelo CARS (SWALES, 1990). Los resultados confirman la movilización de estrategias retóricas proporcionadas por el modelo. Sin embargo, cada área temática utiliza adicionalmente estrategias retóricas peculiares.

Palabras clave: Géneros académicos. Modelo CARS. Artículo científico.

\section{Introdução}

Nas últimas três décadas, pesquisas relacionadas à análise de gêneros têm despertado o interesse de estudiosos por esse vasto e inesgotável campo de investigação. A análise de gêneros, atualmente, pode ser realizada a partir de diferentes perspectivas teóricas, cujos enfoques contemplam desde a função social, a organização e a interrelação entre os gêneros, até reflexões sobre seu ensino, tanto no campo internacional como no contexto brasileiro (BAWARSHI; REIFF, 2013; BEZERRA, 2017).

Compreendendo a importância de estudar os gêneros em contextos particulares, conforme destaca a abordagem de Língua para Fins Específicos (ou, mais particularmente, ESP - English for Specific Purposes), convém ressaltar a esfera acadêmica como um ambiente que concentra um conjunto de práticas de leitura e escrita bastante singulares. Pesquisas recentes apontam a necessidade de refletir sobre essas práticas, incluindo o papel dos gêneros nelas implicados, tendo em vista as dificuldades apresentadas por alunos recém-ingressantes na Universidade para se inserirem nesse novo contexto (BEZERRA, 2015; FISCHER; HOCHSPRUNG, 2017).

Dentre os gêneros que circulam no meio acadêmico e que os graduandos são convidados a ler e a produzir, o artigo científico desfruta de um grande status, por servir como meio de divulgação de estudos realizados, mediando a participação de pesquisadores em eventos acadêmicos e ocupando lugar central nas publicações em 
revistas científicas nos diversos campos disciplinares (MOTTA-ROTH; HENDGES, 2010). Apesar dos crescentes avanços no campo da análise de gêneros, pesquisas que incluam os aspectos textuais, sem se limitarem a eles, como aquelas voltadas para a organização retórica de artigos científicos em diferentes áreas disciplinares, ainda carecem de maior atenção. Para fins aplicados, sobretudo, tais discussões ainda não parecem suficientemente consolidadas, de modo a se considerar o estudo das diferentes estratégias que podem ser mobilizadas na produção do artigo, dependendo da área disciplinar, com vistas à sua didatização.

Tendo em vista a necessidade de apropriação da escrita acadêmica e, em especial, do gênero artigo para o engajamento de graduandos nas práticas discursivas e no processo de produção e publicação científica, esse estudo tem por objetivo analisar, observando as especificidades de cada área, a organização retórica de introduções de artigos científicos escritos por estudantes dos cursos de Letras e de Matemática, produzidos no âmbito do Programa Institucional de Iniciação à Docência (PIBID), da Coordenação de Aperfeiçoamento de Pessoal de Nível Superior (CAPES), em uma Instituição de Ensino Superior pública nordestina. No artigo científico, destacamos a introdução como objeto de estudo, considerando seu caráter estratégico e decisivo para o sucesso do artigo no todo. O corpus deste estudo, portanto, foi constituído por 10 artigos científicos produzidos por discentes bolsistas do PIBID, sendo o5 de cada curso, dos quais se analisou a introdução, com base no Modelo CARS (Create a Research Space) desenvolvido por Swales (1990)ํ.

Para o atingimento do objetivo, buscamos amparo teórico nos postulados dos Estudos Retóricos de Gênero (BAZERMAN, 2011; MILLER, 2012), em combinação com a abordagem de Língua para Fins Específicos (SWALES, 1990). No contexto brasileiro, destacamos, como subsídios para as discussões teóricas aqui levantadas, as pesquisas de Bezerra (2006), Motta-Roth e Hendges (2010) e Biasi-Rodrigues e Bezerra (2012). Convém registrar que para esses estudiosos o gênero tem sido uma maneira de lidar com

\footnotetext{
${ }^{1} \mathrm{O}$ que hoje conhecemos como o Modelo CARS teve tanto uma versão anterior (SWALES, 1984) como uma versão revisada posterior (SWALES, 2004). Neste trabalho, optamos por utilizar a versão "clássica" de 1990, por ser a versão mais popular e mais recorrente em trabalhos baseados na obra do autor, dentre os quais citamos, a título de ilustração, o manual didático de Motta-Roth e Hendges (2010) e o artigo de pesquisa de Bernardino e Valentim (2016).
} 
as características peculiares da escrita situada, constituindo-se em uma maneira de ir além das particularidades formais dos textos para entender o modo como o gênero é percebido e utilizado em situações reais de comunicação.

O presente trabalho encontra-se organizado em cinco seções. A primeira tece considerações sobre o conceito de gênero, enquanto a segunda caracteriza o artigo científico. A terceira apresenta uma descrição do Modelo CARS. A quarta descreve os procedimentos metodológicos utilizados na pesquisa e a quinta apresenta a análise dos dados e a discussão dos resultados encontrados. Vale ressaltar que essa última seção está subdividida em três momentos: o primeiro descreve as análises da área disciplinar de Letras, o segundo se concentra na área disciplinar de Matemática e o terceiro expõe uma comparação entre as duas áreas disciplinares.

\section{Concepções de gênero}

Na literatura especializada, há diferentes concepções no que se refere ao conceito de gênero, talvez devido ao fato de esse termo "veicular diferentes e difusos significados acumulados ao longo da história, especialmente, no âmbito dos estudos literários", conforme Silveira (2005, p. 36). Apesar dos distintos significados que o termo pode assumir, as concepções de gênero, nas abordagens teóricas contemporâneas, concordam em compreender esse conceito como um modo de agir através da linguagem e não meramente como uma entidade formal. Nessa perspectiva, Bawarshi e Reiff (2013) salientam que os gêneros vêm sendo cada vez mais definidos como modos de reconhecer, responder e agir nas interações sociais. Esse entendimento é compatível com o estudo do gênero para além da caracterização de traços formais, que leve em conta, entre outros aspectos relevantes, o seu uso em determinados contextos, a construção de sentidos e os propósitos dos interlocutores e da comunidade em que o gênero circula (BAZERMAN, 2011). Desse modo, torna-se importante partir do ponto de vista definido de forma célebre por Bazerman (2011, p. 23): 
Os gêneros não são apenas formas. Gêneros são formas de vida, modos de ser. São frames para a ação social. São ambientes para a aprendizagem. São os lugares onde o sentido é construído. Os gêneros moldam os pensamentos que formamos e as comunicações através das quais interagimos. Gêneros são os lugares familiares para onde nos dirigimos para criar ações comunicativas inteligíveis uns com os outros e são os modelos que utilizamos para explorar o não-familiar.

Uma vez que estão presentes em nossas ações diárias, na forma como nos organizamos, rotineiramente, formando nossos atos discursivos e cognitivos, os gêneros se constituem como mecanismos para o convívio social e são "propriedades de grupos de indivíduos que geram convenções e padrões que restringem as escolhas individuais" (BIASI-RODRIGUES; HEMAIS; ARAÚJO, 2009, p. 23), ou seja, estão ligados a comunidades discursivas. Nessa perspectiva, os gêneros orientam o modo como os membros de uma comunidade estabelecem regras sociais, reforçam valores e compartilham seus objetivos.

Com vistas a compreender o papel mediador dos gêneros em contextos específicos, em especial, nos contextos acadêmicos e profissionais, a abordagem de Língua para Fins Específicos, representada por Swales (1990), propõe uma definição de gênero que explora, entre outros aspectos, o papel da comunidade discursiva e dos propósitos comunicativos compartilhados pelos seus membros. Esse autor postula que:

Um gênero compreende uma classe de eventos comunicativos, cujos membros compartilham um certo conjunto de propósitos comunicativos. Esses propósitos são reconhecidos pelos membros mais experientes da comunidade discursiva original e, portanto, constituem a razão do gênero. A razão subjacente delineia a estrutura esquemática do discurso e influencia e restringe as escolhas de conteúdo e estilo. (SWALES,199o, p. 58).

Entende-se por classe, nesse contexto, uma categoria prototípica na qual se enquadram textos afins como participantes do mesmo gênero. Já os eventos são utilizados pela comunidade discursiva para alcançar seus objetivos, compartilhados entre os participantes. Nessa perspectiva, os propósitos comunicativos do gênero se tornam "um critério privilegiado que opera no sentido de manter o escopo do gênero [...] estreitamente ligado a uma ação retórica compatível” (SWALES, 1990, p. 58). A categoria de propósito comunicativo é compreendida, nessa concepção, como "a força 
que estabelece o foco na ação retórica do gênero" (BIASI-RODRIGUES; HEMAIS; ARAÚJO, 2009, p. 26). ${ }^{2}$

Compreendemos que o diálogo entre as concepções de gêneros de Língua para Fins Específicos e dos Estudos Retóricos de Gêneros é produtivo porque apresenta contribuições que, combinadas, esclarecem e reforçam uma compreensão equilibrada entre aspectos formais, funcionais e sociocognitivos dos gêneros. Nesse sentido, ao mesmo tempo em que os gêneros apresentam uma estrutura esquemática prototípica moldada pelos propósitos compartilhados pelos membros da comunidade discursiva, também se destaca que esses participantes aprendem a reconhecê-los como "a chave para a compreensão sobre como participar das ações de uma comunidade" (MILLER, 2012, p. 39). Na abordagem da autora, que ressalta os gêneros como ação social tipificada a partir de situações recorrentes, para além de suas regularidades formais, compreendese que eles incorporam e refletem um contexto mais amplo, de caráter social e cultural, em que a linguagem é utilizada. Segundo Bezerra (2006), esse contexto inclui interesses, costumes, valores e hábitos de um grupo social em particular e estabelece regras socialmente aceitáveis para as relações entre escritores e leitores.

A partir da combinação entre as concepções de gênero mencionadas, torna-se possível compreender que a padronização dos gêneros está relacionada aos objetivos do texto, aos objetivos comunicativos dos participantes, bem como a questões ideológicas e a convenções sociais, institucionais, sob as quais os gêneros se desenvolvem e se organizam. Esses padrões característicos dos gêneros precisam ser entendidos e estudados a partir de aspectos sociocomunicativos e funcionais que levem em conta as ações retóricas que eles realizam (MARCUSCHI, 2008; MILLER, 2012)33. Após discutir a noção de gênero que fundamenta este estudo, na sequência tecemos algumas considerações sobre o artigo científico.

\footnotetext{
${ }^{2}$ Ressalte-se que a noção de propósito comunicativo como critério central para a identificação de gêneros é revista por Askehave e Swales (2001) e Swales (2004), que o mantêm como critério relevante, mas não como o único critério para a definição e o reconhecimento do gênero, tendo em vista que os propósitos de um gênero nem sempre são evidentes e que há a necessidade de se considerar outros elementos na análise.

${ }^{3}$ A perspectiva dos Estudos Retóricos de Gênero foi mobilizada para a definição de gênero utilizada neste estudo como um quadro teórico mais amplo e geral. Considerando as limitações de espaço e os propósitos do trabalho, optamos por contemplar na análise apenas as categorias propostas no Modelo CARS.
} 


\section{O gênero artigo científico}

No meio acadêmico, o artigo científico figura como um dos gêneros mais prestigiados em diferentes áreas disciplinares, especialmente por sua função na divulgação dos conhecimentos produzidos pela academia (MOTTA-ROTH; HENDGES, 2010). Além disso, sua importância é reforçada pelo fato de que, em muitas áreas, a produtividade dos pesquisadores é avaliada a partir da publicação de artigos em periódicos científicos, aspecto que gera implicações para o recebimento de promoções, de financiamento de pesquisas e, inclusive, impacta na avaliação dos programas de pósgraduação das universidades.

O artigo científico não só apresenta papel relevante nas interações entre os pesquisadores, membros experientes da comunidade acadêmica, mas também se faz presente no ensino de graduação, seja em atividades de leitura, como objeto de estudo e de análise nas diversas disciplinas, seja no âmbito da produção escrita, como atividade para avaliação curricular ou como recurso para o desenvolvimento dos letramentos dos estudantes, em atividades supervisionadas por um professor-orientador. Dentre as atividades que permitem a inserção dos estudantes em práticas acadêmicas que envolvem o artigo científico, é possível citar os Trabalhos de Conclusão de Curso e programas institucionais como o PIBID, que elegemos como locus do estudo. O PIBID 4 , apesar de ter como foco a iniciação à docência, integra essa experiência à escrita acadêmica, exigindo a produção de um relatório no formato de artigo científico.

\footnotetext{
${ }_{4}^{4}$ O Programa Institucional de Bolsa de Iniciação à Docência (PIBID) se constitui como política nacional de formação de professores do Ministério da Educação e Cultura (MEC). Essa ação foi implementada pela Coordenação de Aperfeiçoamento de Pessoal de Nível Superior (CAPES) e pelo Fundo Nacional de Desenvolvimento da Educação (FNDE), com o objetivo de proporcionar aos discentes uma aproximação com o cotidiano das escolas públicas de educação básica. O primeiro Edital MEC/CAPES/FNDE foi lançado no ano de 2007, porém o programa só iniciou em 2009, por força de portaria. O PIBID visa incentivar a valorização e a formação de professores para atuarem nas Escolas de Educação Básica (EEB), estabelecendo uma ponte entre as Instituições de Ensino Superior.
} 
Tendo em vista a centralidade do artigo no ambiente acadêmico, diversos estudos, sob diferentes perspectivas teóricas, têm sido desenvolvidos sobre esse gênero. Dentre eles, incluem-se orientações sobre sua produção, a exemplo da obra de Gustavii (2017), na qual o autor apresenta uma espécie de guia introdutório para orientar escritores iniciantes sobre como organizar e publicar artigos. Inicialmente desenvolvido a partir da área de ciências médicas e biológicas, ao longo de suas reedições foram acrescentados exemplos de outras áreas, partindo do pressuposto de que "o princípio da escrita científica é o mesmo para todas as disciplinas" (GUSTAVII, 2017, p. 5). Semelhantemente ao que costuma ocorrer em manuais de metodologia científica, essa visão acerca do artigo é generalizante e não enfatiza as particularidades da organização do conhecimento nos diferentes campos disciplinares.

Por outro lado, é possível encontrar na literatura especializada relatos de experiência sobre o ensino desse gênero e sobre o seu papel no processo de desenvolvimento de letramentos acadêmicos. O estudo de Bezerra (2015), por exemplo, investiga como estudantes de graduação constroem suas identidades acadêmicas, por meio da análise das estratégias de gerenciamento das vozes com que dialogam ao produzir seus próprios artigos científicos. Ainda na perspectiva do ensino, Pereira, Basílio e Leitão (2017), embasadas no aporte teórico-metodológico do Interacionismo Sociodiscursivo (ISD), consideram que o artigo se configura como gênero caleidoscópico realizado por microações de linguagem.

Outra perspectiva em que os estudos sobre o artigo são fecundos é o Inglês para Fins Específicos (ESP), que se debruçam sobre a caracterização de sua organização retórica em diferentes áreas disciplinares, desde os estudos originais de Swales (1990) até estudos posteriores como os de Ritti-Dias e Bezerra (2013) e Bernardino e Pacheco (2017), que serão comentados adiante. Seja a partir de uma abordagem mais generalizada e normativa tal como se encontra em manuais, de uma caracterização mais ampla aliada aos letramentos, de uma reflexão sobre a sua didatização ou da análise de sua organização sociorretórica, os estudos e pesquisas sobre o artigo convergem para o reconhecimento da complexidade do gênero.

Um aspecto dessa complexidade está na autoria, visto que textos nesse gênero podem ser produzidos tanto por participantes especializados quanto por participantes 
periféricos da comunidade acadêmica. Essa especialização dos participantes (ou a falta dela) acarreta implicações significativas para: (i) a configuração dos textos, visto que, como aponta Swales (1990), por um lado, os especialistas dominam as convenções dos gêneros e em geral produzem exemplares mais prototípicos, de acordo com as expectativas da comunidade e, por outro lado, são mais livres para explorar criativamente os limites do gênero, enquanto os participantes periféricos são convidados a reproduzir os padrões estabelecidos, podendo sua "criatividade" ser penalizada e avaliada como ruptura com o gênero; (ii) a circulação dos textos, ilustrada pelo acesso dos participantes especializados a veículos de publicação mais prestigiados e mais bem avaliados, enquanto os participantes periféricos dispõem de espaços mais limitados para a circulação de suas produções; (iii) as relações ideológicas, de poder e de identidade, em decorrência das quais aos participantes especializados é concedida mais liberdade para expressar sua voz no texto, dialogando de maneira mais igualitária com seus pares e até os confrontando, enquanto os participantes periféricos tendem a utilizar estratégias de reprodução mais literal e de concordância com os teóricos (FIGUEIREDO; BONINI, 2006; MACEDO; PAGANO, 2011; OLIVEIRA, 2015).

Conforme Motta-Roth e Hendges (2010), a organização geral do artigo nas diferentes áreas obedece à estrutura conhecida como IMRD (Introdução, Metodologia, Resultados e Discussão). Cada seção se organiza a partir da mobilização de estratégias retóricas específicas, marcadas pelas características linguístico-discursivas impressas no gênero pela esfera acadêmica, a fim de garantir que os textos produzidos nesse gênero cumpram os propósitos a que se destinam, em especial, o de divulgar determinada pesquisa. Essa organização geral também é confirmada pelo estudo de Cotos, Huffman e Link (2015), no qual os autores utilizam uma ferramenta computacional para analisar a organização retórica de 150 artigos provenientes de 30 diferentes disciplinas das áreas de Ciências Humanas, Ciências Sociais e Ciências Naturais e Aplicadas.

Contudo, tanto Swales (1990) como Motta-Roth e Hendges (2010) ressaltam que a estrutura IMRD é flexível e, dependendo das convenções de cada área, é possível suprimir seções (por exemplo, a seção de metodologia, descrevendo os aspectos metodológicos na introdução ou na seção de resultados) ou acrescentar outras (a exemplo dos tópicos de fundamentação teórica e de considerações finais). Essa 
flexibilidade ilustra o caráter dinâmico e situado dos gêneros e, no caso do artigo científico, é importante salientar que as variações em sua construção são sensíveis, por exemplo, à natureza da pesquisa relatada no texto (ou seja, se se trata de um estudo experimental ou de natureza bibliográfica), à cultura ou país em que o artigo é publicado e às características da área disciplinar em que ele circula. Além disso, há variação na própria nomeação das seções do gênero, como demonstram as possibilidades de nomeação da seção final (conclusão, conclusões, considerações finais ou últimas palavras). Todos esses aspectos sinalizam que as diferentes áreas organizam o conhecimento produzido de maneiras particulares (HYLAND, 2004).

Considerando a produção do artigo em uma área disciplinar específica, Paiva (2019) propõe, com base na perspectiva swalesiana, um modelo descritivo da organização retórica do gênero Artigo Acadêmico Experimental (AAE), a partir da análise de textos produzidos por estudantes de um curso de Letras. O esquema é composto por nove movimentos e trinta e cinco passos recorrentes, distribuídos em cinco seções: Introdução, Revisão de Literatura, Metodologia, Resultados e Discussão e Conclusão(ões). Independentemente da quantidade e do nome das seções, é inquestionável que os artigos científicos apresentam introduções como seções iniciais.

Uma vez que a análise dos textos neste trabalho centra-se no Modelo CARS para a descrição da introdução de artigos (SWALES, 1990), consideramos pertinente apresentar a descrição do referido modelo.

\section{O modelo CARS}

O Modelo CARS representa uma contribuição teórico-metodológica de Swales (1990), no campo da Análise de Gêneros, como ressaltam Biasi-Rodrigues, Hemais e Araújo (2009). Para a elaboração do referido modelo, em estudo seminal, Swales (1990) utiliza uma metáfora ecológica para nomeação dos movimentos retóricos (moves), apoiando-se no estudo de introduções de artigos de pesquisa de diferentes áreas disciplinares, no intuito de analisar as estratégias que os autores utilizam para distribuir 
as informações nos textos. Para melhor visualização, o Modelo CARS encontra-se sintetizado abaixo:

Quadro 1 - Modelo CARS para introdução de artigo de pesquisa

\begin{tabular}{|c|c|c|}
\hline $\begin{array}{c}\text { Movimento } 1 \\
\text { Estabelecer um território }\end{array}$ & $\begin{array}{l}\text { Passo } 1 \text { - Estabelecer a importância da pesquisa } \\
\text { Passo } 2 \text { - Fazer generalização sobre o assunto } \\
\text { Passo } 3 \text { - Revisar itens de pesquisas anteriores }\end{array}$ & $\begin{array}{l}\text { e/ou } \\
\text { e/ou }\end{array}$ \\
\hline $\begin{array}{c}\text { Movimento } 2 \\
\text { Estabelecer um nicho }\end{array}$ & $\begin{array}{l}\text { Passo 1A - Contra-argumentar } \\
\text { Passo 1B - Identificar lacunas no conhecimento } \\
\text { Passo1C - Fazer questionamentos } \\
\text { Passo 1D - Continuar uma tradição }\end{array}$ & $\begin{array}{l}\text { ou } \\
\text { ou } \\
\text { ou }\end{array}$ \\
\hline $\begin{array}{c}\text { Movimento } 3 \\
\text { Ocupar o nicho }\end{array}$ & $\begin{array}{l}\text { Passo 1A - Esboçar os objetivos } \\
\text { Passo } 1 \mathrm{~B} \text { - Anunciar a presente pesquisa } \\
\text { Passo } 2 \text { - Apresentar os principais resultados } \\
\text { Passo } 3 \text { - Indicar a estrutura do artigo }\end{array}$ & ou \\
\hline
\end{tabular}

Fonte: Swales (1990, p. 141)

Como mostra o quadro, Swales (1990) faz uma representação esquemática da introdução do artigo científico, por meio de categorias denominadas como movimentos (moves), as quais recobrem subcategorias identificadas como passos (steps), que podem excluir-se ou acrescentar-se uns aos outros, com o objetivo de descrever a organização retórica da introdução a partir da distribuição de informações recorrentes.

Como destacado por Biasi-Rodrigues, Hemais e Araújo (2009), por se configurar como um modelo simples, maleável e passível de alterações, ele tem sido adaptado para a análise das diferentes seções do artigo científico, bem como para a descrição integral de outros gêneros, inclusive provenientes de domínios diferentes do acadêmico. No Brasil, essa perspectiva tem sido frutífera e influenciou, desde meados da década de 1990, diversos estudos, alguns dos quais já mencionados neste trabalho.

Nesse sentido, a título de exemplificação, dado o enfoque do nosso estudo, salientamos as pesquisas que direcionam o olhar para a organização retórica de gêneros da escrita acadêmica, como os de Motta-Roth (1995), que realizou a análise de resenhas de livros em inglês em três áreas disciplinares; de Araújo (1996), que analisou a estrutura 
retórica de resenhas de livro de linguística, também em inglês; de Bezerra (2002), que descreveu a organização retórica de resenhas da área de Teologia; de Ritti-Dias e Bezerra (2013), que analisaram a organização retórica de introduções de artigos científicos na área de saúde pública; de Florek (2017), que tratou da organização retórica do resumo acadêmico gráfico; e de Oliveira (2017), que investigou a organização retórica do resumo de comunicação para eventos acadêmicos.

No que se refere especificamente à análise da introdução de artigos, destacamos as contribuições de Bernardino e Abreu (2017), a respeito da seção de introdução em artigos acadêmicos experimentais da cultura disciplinar de psicologia e de Bernardino e Pacheco (2017), que analisam a seção introdutória de artigos da cultura disciplinar de nutrição. Apesar de reconhecer a relevância dos trabalhos mencionados, nesta pesquisa optamos por embasar nossa análise no Modelo CARS original, reiterando a importante contribuição metodológica de Swales (1990) para analisar como os movimentos retóricos se realizam nas introduções dos artigos que compõem o corpus desta investigação. A seguir, apresentamos a metodologia do estudo.

\section{Metodologia}

Para a consecução do objetivo deste estudo, analisamos um corpus constituído por $10^{5}$ introduções de artigos científicos das áreas disciplinares de Letras e de Matemática, sendo 5 de cada área. Os artigos, disponibilizados por professores coordenadores das referidas áreas, foram produzidos por estudantes bolsistas do PIBID, cursando o sétimo período nos dois cursos, em uma universidade pública nordestina. Os artigos atendem à exigência de elaboração de um relatório final das atividades, a ser submetido à plataforma do Programa. No que se refere à circulação dos textos, após a

\footnotetext{
${ }^{5}$ Neste estudo, de natureza exploratória, não se pretendeu chegar a resultados generalizáveis sobre a organização retórica dos trabalhos dos alunos, mas a indicações e conclusões preliminares que serão exploradas e ampliadas em uma pesquisa maior, em andamento. Os textos aqui discutidos, portanto, são apenas uma amostra do corpus a ser considerado na referida pesquisa.
} 
finalização da pesquisa, os estudantes são incentivados pelos respectivos orientadores a divulgar seus resultados em eventos científicos ou em publicações organizadas como contrapartida ao órgão de fomento. Para fins de referenciação ao longo da análise, utilizamos os códigos AL para os artigos de Letras e AM para os de Matemática, seguidos de uma numeração sequencial (AL1... AM1...).

Para a obtenção dos resultados, empreendemos uma análise minuciosa de cada introdução, verificando, cuidadosamente, sua organização retórica (movimentos e passos), a partir do Modelo CARS. Observamos quais movimentos e passos foram realizados, especificamente, em cada área, bem como as ocorrências comuns às duas áreas disciplinares.

É pertinente pontuar ainda que, para a verificação das estratégias retóricas caracterizadoras da seção introdutória dos artigos, consideramos movimentos e passos recorrentes aqueles que apresentaram frequência igual ou superior a 5 dentre os 10 artigos analisados. Julgamos como pouco recorrentes aqueles que apresentaram frequência entre 2 e 4 e como insuficientemente recorrentes os que apresentaram frequência abaixo de 2. Esses últimos foram desconsiderados na análise e discussão dos resultados.

Os resultados revelados foram dispostos em tabelas com as respectivas quantidades, demonstrando as recorrências dos movimentos retóricos nas introduções de artigos, para posterior análise qualitativa. Esses aspectos serão detalhados na próxima seção.

\section{Análise dos dados e discussão dos resultados}

Esta seção está subdividida em três momentos: o primeiro apresenta as análises da área disciplinar de Letras, o segundo exibe as análises da área disciplinar de Matemática e o terceiro expõe uma comparação entre as duas áreas, observando as especificidades bem como o que é comum entre elas. No decorrer das análises, apresentamos exemplos ilustrativos das realizações recorrentes. Nesses exemplos, 
privilegiamos as incidências mais recorrentes, por sinalizarem as estratégias preferidas pelos autores dos artigos e assim mostrarem maior impacto para a caracterização da organização retórica nas introduções em cada uma das áreas.

\subsection{A organização retórica de introduções de artigos científicos na área de Letras}

Tendo em vista a proposta de organização retórica de Swales (1990), percebemos, na análise das 05 introduções da área de Letras, a presença recorrente dos Movimentos 1 (Estabelecer um território) e 3 (Ocupar o nicho), enquanto o Movimento 2 (Estabelecer um nicho) mostrou-se pouco recorrente. Estudos anteriores, desde aqueles reportados por Connor (1996) até Ritti-Dias e Bezerra (2013), já sinalizavam a fraca realização do Movimento 2 em artigos originários de culturas diferentes da norte-americana, locus da análise de Swales (1990). Em revisão do Modelo CARS (1990), o próprio Swales (2004) reduz a quantidade de passos do Movimento 2, entendendo que estratégias como contra-argumentar ou levantar questionamentos não seriam, "funcionalmente [itálicos no original], muito diferentes de indicar lacunas" (SWALES, 2004, p. 230) na área da pesquisa. Apresentamos na Tabela 1 a sistematização das ocorrências dos movimentos retóricos em introduções de artigos científicos na área de Letras, incluindo passos (estratégias retóricas) adicionais que apareceram no corpus, embora não previstos no modelo:

Tabela 1 - Organização retórica da introdução de artigos na área de Letras

\begin{tabular}{|c|c|c|c|c|c|c|}
\hline & $\mathrm{AL}$ & $\mathrm{AL}$ & $\mathrm{AL}$ & $\mathrm{AL}$ & $\mathrm{AL}$ & Ocorrências \\
\hline Quantidade de palavras na Introdução & 554 & 354 & 645 & 1286 & 561 & 5 \\
\hline Movimento 1: Estabelecer um território & & & & & & \\
\hline $\begin{array}{c}\text { Passo 1: Estabelecendo a importância da } \\
\text { pesquisa e/ou }\end{array}$ & & $\mathrm{X}$ & $\mathrm{X}$ & $\mathrm{X}$ & & 3 \\
\hline
\end{tabular}




\begin{tabular}{|c|c|c|c|c|c|c|}
\hline $\begin{array}{l}\text { Passo 2: Fazendo generalizações sobre o } \\
\text { assunto e/ou }\end{array}$ & $\mathrm{X}$ & $\mathrm{X}$ & $\mathrm{X}$ & $\mathrm{X}$ & & 4 \\
\hline $\begin{array}{l}\text { Passo 3: Revisando itens de pesquisas } \\
\text { anteriores }\end{array}$ & $\mathrm{X}$ & & $\mathrm{X}$ & $\mathrm{X}$ & $\mathrm{X}$ & 4 \\
\hline \multicolumn{7}{|l|}{ Movimento 2: Estabelecer um nicho } \\
\hline Passo ıA: Contra-argumentando ou & & & & & & o \\
\hline Passo 1B: Indicando uma lacuna ou & & & & & & o \\
\hline Passo 1C: Levantando questões ou & & & & $\mathrm{X}$ & & 1 \\
\hline Passo 1D: Continuando uma tradição & $\mathrm{X}$ & & & $\mathrm{X}$ & & 2 \\
\hline \multicolumn{7}{|l|}{ Movimento 3: Ocupar o nicho } \\
\hline Passo 1A: Esboçando os objetivos ou & $\mathrm{X}$ & $\mathrm{X}$ & $\mathrm{X}$ & $\mathrm{X}$ & $\mathrm{X}$ & 5 \\
\hline Passo 1B: Anunciando a pesquisa & & & $\mathrm{X}$ & $\mathrm{X}$ & $\mathrm{X}$ & 3 \\
\hline $\begin{array}{l}\text { Passo 2: Apresentando os principais } \\
\text { resultados }\end{array}$ & $\mathrm{X}$ & & & $\mathrm{X}$ & & 2 \\
\hline Passo 3: Indicando a estrutura do artigo & $\mathrm{X}$ & $\mathrm{X}$ & $\mathrm{X}$ & $\mathrm{X}$ & $\mathrm{X}$ & 5 \\
\hline $\begin{array}{c}\text { Passo 4: Descrevendo procedimentos } \\
\text { metodológicos }\end{array}$ & $\mathrm{X}$ & $\mathrm{X}$ & $\mathrm{X}$ & $\mathrm{X}$ & $\mathrm{X}$ & 5 \\
\hline Passo 5: Vinculando o estudo a um projeto & $\mathrm{X}$ & $\mathrm{X}$ & $\mathrm{X}$ & $\mathrm{X}$ & $\mathrm{X}$ & 5 \\
\hline
\end{tabular}

Fonte: Elaboração dos autores

Os alunos de Letras realizaram o Movimento "Estabelecer um território" através dos passos 1 (Estabelecendo a importância da pesquisa), 2 (Fazendo generalizações sobre o assunto) e 3 (Revisando itens de pesquisas anteriores), que apresentaram frequências respectivas de 3, 4 e 4 ocorrências no corpus. No Exemplo 1, o Passo 2 do Movimento 1, um dos mais recorrentes no corpus, é realizado através da referência a "toda prática comunicativa”, extrapolando a importância dos gêneros, conforme vista pelo autor, para além das práticas sobre as quais o trabalho se debruça. Outro passo recorrente no Movimento 1 foi o 3, realizado frequentemente através de citações diretas, apresentando a contribuição de pesquisas anteriores, o qual está representado no Exemplo 2, a seguir:

Exemplo 1 [M1P2 - AL1] - Fazendo generalizações sobre o assunto

\footnotetext{
${ }^{6}$ Os passos 4 e 5 do Movimento 3, em destaque na tabela, não estão previstos no modelo CARS (SWALES, 1990). A discussão dessas estratégias retóricas encontradas no corpus é realizada na sequência, após a exemplificação dos passos anteriores.
} 
Dessa forma, entende-se que os gêneros são essenciais para a realização de toda prática comunicativa.

Exemplo $2\left[\mathrm{M}_{1} \mathrm{P}_{3}-\mathrm{AL}_{4}\right]-$ Revisando itens de pesquisas anteriores

[...] destaca-se a concepção de Bazerman (2011, p.23), demonstrando que os "gêneros não são apenas formas. Gêneros são formas de vida, modos de ser".

O Movimento 3 (Ocupar o nicho) foi representado no corpus especialmente pelos passos 1A (Esboçando os objetivos) e 3 (Indicando a estrutura do artigo), que foram empregados na totalidade das introduções analisadas, e pelo passo $1 \mathrm{~B}$ (Anunciando $a$ pesquisa), presente em 3 das 5 introduções. A realização do Passo $1 \mathrm{~A}$ (Esboçando os objetivos) é ilustrada pelo Exemplo 3, em que se podem notar elementos léxicogramaticais típicos dessa estratégia retórica, como o termo “objetivo" e expressões como “o presente estudo”. Já no Exemplo 4, o Passo 3 se realiza como um recurso metadiscursivo que permite ao autor orientar o leitor sobre a forma de organização do artigo:

Exemplo $3\left[\mathrm{M}_{3} \mathrm{P} 1 \mathrm{~A}-\mathrm{AL}_{3}\right]$ - Esboçando os objetivos

O presente estudo tem como objetivo analisar os aspectos textual-interativos que organizam o diálogo entre alunos no aplicativo WhatsApp.

Exemplo 4 [M3 $\left.\mathrm{M}_{3}-\mathrm{AL1}\right]$ - Indicando a estrutura do artigo

Retoricamente, este artigo encontra-se estruturado em três seções, assim delineadas: A primeira tece considerações sobre gêneros, [...] A segunda traz discussões sobre [...] A terceira apresenta a pesquisa de campo, com procedência e análise do corpus.

É pertinente destacar que, além dos passos que constituem o Modelo CARS, observamos a realização recorrente de duas novas estratégias: Descrevendo procedimentos metodológicos 7 e Vinculando o estudo a um projeto (presentes na totalidade das introduções). Esses passos excedentes foram acrescentados ao Movimento 3 (Ocupar o nicho), uma vez que contribuem para mostrar “como esse nicho, no ambiente mais amplo, será ocupado e defendido" (SWALES, 1990, p. 142). A

\footnotetext{
7 A ocorrência de referências a procedimentos metodológicos nas introduções de artigos, embora não prevista pelo Modelo CARS (1990), é reconhecida posteriormente por Swales (2004).
} 
realização dos referidos passos pode ser observada, respectivamente, nos exemplos 5 e 6, a seguir:

Exemplo $5\left[\mathrm{M}_{3} \mathrm{P}_{4}-\mathrm{AL}_{5}\right]$ - Destacando procedimentos metodológicos

É pertinente salientar que os dados desta pesquisa foram coletados por meio de sequência didática, a partir da leitura e discussão e produção do gênero textual Limerique.

Exemplo $6\left[\mathrm{M}_{3} \mathrm{P}_{5}-\mathrm{AL}_{2}\right]$ - Vinculando o estudo a um projeto

Este estudo resulta da participação do subprojeto [...] vinculado ao programa Institucional de Bolsa de iniciação à docência PIBID/CAPES/UNEAL.

No Exemplo 5, percebemos como autor apresenta a metodologia usada para coleta dos dados marcada, lexicalmente, pela expressão "os dados desta pesquisa foram coletados...", a fim de esclarecer o leitor sobre o processo de construção do corpus que é analisado no trabalho. Já o segundo passo peculiar ao nosso corpus é realizado por meio da expressão "Este estudo resulta da participação de (o)", sinalizando o projeto ao qual está vinculado o trabalho.

Essas realizações adicionais nos permitem compreender que, na área disciplinar de Letras, de acordo com a amostra em análise, os autores acham pertinente apresentar o projeto ao qual a pesquisa está relacionada, bem como deixar claro para o leitor os procedimentos metodológicos utilizados para construção do estudo, uma vez que tais ações foram realizadas em todas as introduções que compõem nosso corpus. No conjunto, a ocorrência de estratégias retóricas não previstas pelo modelo, ao lado dos passos estabelecidos, longe de invalidá-lo, mostra seu potencial de captar tanto a estabilidade como a dinamicidade inerente ao gênero, evidenciando a aplicabilidade do modelo a diferentes áreas disciplinares.

Por fim, destacamos aqueles passos que não tiveram nenhuma ocorrência no corpus analisado: $1 \mathrm{~A}$ e $1 \mathrm{~B}$ do Movimento 2, respectivamente Contra-argumentando e Indicando uma lacuna. Os demais passos desse Movimento também tiveram baixa ocorrência. Esses dados sugerem certa especialização dessas estratégias retóricas, confirmando o que já apontava Swales (2004). As nossas hipóteses para explicar a ausência desses passos na amostra analisada são, por um lado, o fato de eles 
necessitarem de um forte caráter argumentativo para sua realização, que os estudantes, como membros iniciantes nas práticas discursivas da comunidade acadêmica, ainda não têm segurança para utilizar; por outro lado, o tipo de pesquisa desenvolvida pelos pibidianos, que, de modo geral, envolve a descrição e o relato de sequências de atividades vivenciadas nas escolas públicas, privilegiando a contextualização e a caracterização da pesquisa, realizadas através dos Movimentos 1 e 3 do modelo.

\subsection{A organização retórica de introduções de artigos científicos na área de}

\section{Matemática}

Quanto à análise dos movimentos retóricos presentes nas introduções de artigos científicos da área de Matemática, observamos recorrências do Movimento 1 (Estabelecer um território) e do Movimento 3 (Ocupar o nicho). Já o Movimento 2 (Estabelecer um nicho) não foi recorrente, assim como ocorreu nos textos da área de Letras. Na Tabela 2, a seguir, sistematizamos as realizações para a área de Matemática:

Tabela 2 - Organização retórica da introdução de artigos na área de Matemática

\begin{tabular}{|c|c|c|c|c|c|c|}
\hline & AM & AM & AM & AM & AM & Ocorrências \\
\hline Quantidade de palavras na & 228 & 245 & 202 & 244 & 377 & 5 \\
Introdução & & & & & & \\
\hline MOVE 1: Estabelecer um território & & & & & & \\
\hline $\begin{array}{c}\text { Passo 1: Estabelecendo a } \\
\text { importância da pesquisa e/ou }\end{array}$ & $\mathrm{X}$ & & & $\mathrm{X}$ & & 2 \\
\hline $\begin{array}{c}\text { Passo 2: Fazendo generalizações } \\
\text { sobre o assunto e/ou }\end{array}$ & $\mathrm{X}$ & $\mathrm{X}$ & $\mathrm{X}$ & & $\mathrm{X}$ & \\
\hline $\begin{array}{c}\text { Passo 3: Revisando itens de } \\
\text { pesquisas anteriores }\end{array}$ & $\mathrm{X}$ & $\mathrm{X}$ & & $\mathrm{X}$ & $\mathrm{X}$ & \\
\hline MOVE2: Estabelecendo um nicho & & & & & & \\
\hline $\begin{array}{c}\text { Passo 1A: Contra-argumentando ou } \\
\text { Pand }\end{array}$ & & & & & & \\
\hline
\end{tabular}




\begin{tabular}{|c|c|c|c|c|c|c|}
\hline Passo 1B: Indicando uma lacuna ou & & & & & & \\
\hline Passo 1C: Levantando questões ou & & & & & & \\
\hline $\begin{array}{c}\text { Passo 1D: Continuando uma } \\
\text { tradição }\end{array}$ & & & & & & \\
\hline MOVE 3: Ocupando o nicho & & & & & & \\
\hline Passo 1A: Esboçando os objetivos ou & $\mathrm{X}$ & $\mathrm{X}$ & $\mathrm{X}$ & $\mathrm{X}$ & $\mathrm{X}$ & 5 \\
\hline $\begin{array}{c}\text { Passo 1B: Anunciando a presente } \\
\text { pesquisa }\end{array}$ & & & $\mathrm{X}$ & $\mathrm{X}$ & & 2 \\
\hline $\begin{array}{c}\text { Passo 2: Apresentando os principais } \\
\text { resultados }\end{array}$ & & & & & & \\
\hline $\begin{array}{c}\text { Passo 3: Indicando a estrutura do } \\
\text { Artigo }\end{array}$ & & $\mathrm{X}$ & $\mathrm{X}$ & & $\mathrm{X}$ & 3 \\
\hline $\begin{array}{c}\text { Passo 4: Descrevendo } \\
\text { procedimentos metodológicos }\end{array}$ & $\mathrm{X}$ & $\mathrm{X}$ & & $\mathrm{X}$ & $\mathrm{X}$ & 4 \\
\hline
\end{tabular}

Fonte: Elaboração dos autores

Referente ao Movimento 1 (Estabelecer um território), observamos dois passos recorrentes, a saber: o 2 (Fazendo generalizações sobre o assunto) e o 3 (Revisando itens de pesquisa anteriores), presentes em 4 introduções. No Exemplo 7, o Passo 2 do Movimento 1 é marcado, semanticamente, pela ideia da complexidade da definição de matemática. Para isso, o autor do artigo generaliza a ideia de que tal complexidade se dê pela amplitude dos conceitos e definições. Já no Exemplo 8, demonstramos a estratégia utilizada pelo autor para revisar pesquisas anteriores. Neste caso, o estudante fez uso de citação direta:

Exemplo 7 [M1P2 - AM2 $]$ - Fazendo generalizações sobre o assunto

Por ser um campo muito vasto e repleto de conceitos e definições, a matemática acaba sendo um obstáculo na vida do estudante.

Exemplo $8\left[\mathrm{M}_{1} \mathrm{P}_{3}-\mathrm{AM}_{3}\right]-$ Revisando itens de pesquisas anteriores

De acordo com Lorenzato (2006, p.30) "a experiência tem mostrado que o MDM facilita a aprendizagem [...]". 
Quanto ao Movimento 3 (Ocupar o nicho), ele esteve presente em todas as amostras analisadas nas duas áreas disciplinares representadas neste estudo e, no caso de Matemática, as introduções apresentaram pelo menos dois passos desse movimento. Observamos que o passo 1A (Esboçando os objetivos) foi o de maior recorrência, com frequência de $100 \%$ nos textos, e o passo 3 (Indicando a estrutura do artigo) também foi recorrente, presente em 3 das 5 introduções. Já o passo $1 \mathrm{~B}$ (Anunciando a presente pesquisa) foi pouco recorrente, tendo a realização em apenas 2 introduções. No Exemplo 9, a seguir, o passo $1 \mathrm{~A}$ do Movimento 3, é apresentado a partir das expressões "visando relacionar" e "no intuito", através das quais o autor se refere ao objetivo do estudo. Já no Exemplo 10, o passo 3 do Movimento 3 é marcado lexicalmente pela sentença "A estrutura do estudo...", a fim de situar o leitor sobre as seções que compõem o artigo:

Exemplo 9 [M3 $\mathrm{M}_{3} \mathrm{~A}$ - AM2] - Esboçando os Objetivos

[...] foi realizado o exercício prático desse instrumento, visando relacionar a matemática discutida no contexto escolar com situações reais, no intuito de investir no processo de compreensão matemática.

Exemplo $10\left[\mathrm{M}_{3} \mathrm{P}_{3}-\mathrm{AM}_{5}\right]$ - Indicando a Estrutura do Artigo

A estrutura deste estudo compreende-se em três momentos. O primeiro traz uma abordagem [...] o segundo traz uma discussão [...] no terceiro traz o experimento realizado na aula prática[...].

Após o levantamento da recorrência dos movimentos e passos, percebemos que a construção da introdução do artigo na área de Matemática se fez, principalmente, a partir da realização do Movimento Retórico 3 (Ocupar o nicho). Isso talvez se justifique pela maior objetividade característica dos textos, em comparação com os de Letras, em que também observamos um investimento expressivo dos autores nas estratégias retóricas do Movimento 1. Enquanto uma introdução em Letras chega a 1286 palavras (AL4), as introduções dos artigos de Matemática apresentam no máximo 377 palavras ( $\left.\mathrm{AM}_{5}\right)$.

Como é possível observar na Tabela 2, o Movimento 2 (Estabelecer o nicho) não se confirmou em Matemática. Embora se trate de um corpus reduzido, que não permite nem pretende fazer generalizações, o resultado sugere que as ações retóricas previstas 
no Movimento 2 não são relevantes para a construção da introdução do artigo na área disciplinar de Matemática, semelhantemente ao que aconteceu nos artigos da área de Letras. Neste sentido, é possível que o perfil dos estudantes como participantes periféricos da comunidade acadêmica e a natureza das pesquisas tenham um papel relevante nessa correlação. No que se refere a estratégias não previstas, também em Matemática verificamos a ocorrência do passo Descrevendo procedimentos metodológicos:

Exemplo $11\left[\mathrm{M}_{3} \mathrm{P}_{4}-\mathrm{AM}\right]$ - Descrevendo procedimentos metodológicos

Pensando nisso foi elaborado um estudo através de uma aula prática aplicada em sala de aula, no curso de licenciatura em matemática, na disciplina Laboratório de Ensino I.

Esse passo adicional pode ser considerado como característico da escrita da área disciplinar de Matemática, na amostra sob análise, visto que ocorreu em 4 das 5 introduções analisadas. As demais estratégias retóricas correspondem ao que é previsto pelo modelo $C A R S$, confirmando também a sua aplicabilidade a essa área.

\section{$5 \cdot 3$ Um olhar para as duas áreas disciplinares}

Os textos escritos no contexto acadêmico são compreendidos a partir de sua função social, pois são formas de discurso específico inerentes a cada área disciplinar. Nessa perspectiva, Swales (1990) supõe que as distintas comunidades acadêmicas são identificáveis por meio de discursos convencionais específicos. Isso significa dizer que cada área disciplinar apresenta suas peculiaridades, o que não significa a inexistência de aspectos em comum entre elas. Assim, considerando as áreas de Letras e Matemática, levantamos alguns questionamentos no que tange à realização dos movimentos retóricos na escrita da introdução do artigo: quais foram os movimentos e passos recorrentes nas duas áreas? Quais foram as recorrências específicas de cada área? 
Sistematizamos na Tabela 3 os movimentos e passos mais recorrentes nos 10 textos, com frequência igual ou superior a três ocorrências nas introduções de cada área.

Tabela 3 - Estratégias retóricas recorrentes nas áreas de Letras e Matemática

\begin{tabular}{|c|c|c|}
\hline MOVE 1: Estabelecer um território & LETRAS & MATEMÁTICA \\
\hline Passo 1: Estabelecendo a importância da pesquisa & $3 / 5$ & - \\
\hline Passo 2: Fazendo generalizações sobre o assunto & $4 / 5$ & $4 / 5$ \\
\hline Passo 3: Revisando itens de pesquisas prévias & $4 / 5$ & $4 / 5$ \\
\hline MOVE 3: Ocupar o nicho & & $5 / 5$ \\
\hline Passo 1A: Esboçando os objetivos ou & $5 / 5$ & $3 / 5$ \\
\hline Passo 3: Indicando a estrutura do Artigo & $5 / 5$ & $4 / 5$ \\
\hline Passo 4: Descrevendo procedimentos & $5 / 5$ & \\
\hline Passo 5: Vinculando o estudo a um projeto & $5 / 5$ & - \\
\hline
\end{tabular}

Fonte: Elaboração dos autores

O delineamento das estratégias retóricas (movimentos e passos) que compõem a introdução do artigo científico se apoia em convenções estabelecidas em cada área disciplinar. Cada área tem suas convenções, sua cultura própria, o que se traduz em objetos de estudos singulares e modos particulares de argumentar, refletir e discutir sobre as questões específicas. No entanto, mesmo áreas bastante distintas como Letras e Matemática também apresentam pontos em comum nas formas de construir o discurso científico.

Assim, observamos, neste estudo, que as estratégias comuns às duas áreas disciplinares incluíram a generalização sobre o assunto abordado, a revisão de pesquisas anteriores, a apresentação dos objetivos e a indicação da estrutura do artigo. Essas estratégias constituem, no Modelo $C A R S$, passos integrantes dos movimentos retóricos 1 e 3. Quanto aos passos não previstos pelo modelo de análise, apenas a indicação de procedimentos metodológicos foi recorrente nas duas áreas.

Essas observações sugerem que as estratégias comuns às áreas possibilitam ações retóricas voltadas aos propósitos comunicativos do gênero artigo científico e não 
parecem estar vinculados a uma área específica. Quanto às particularidades da introdução do artigo em cada área disciplinar, os quadros a seguir sistematizam a organização retórica da introdução do artigo em cada área conforme revelada por nossos dados. Para maior coerência do quadro revelado pela análise, o Movimento 3 de Swales (1990) se torna o nosso Movimento 2 e os respectivos passos recebem uma nova numeração sequencial de acordo com sua presença nos textos.

Quadro 2 - Organização retórica da introdução do artigo em Letras

\begin{tabular}{|c|lc|}
\hline \multirow{2}{*}{$\begin{array}{c}\text { Movimento 1 } \\
\text { Estabelecer um território }\end{array}$} & Passo 1: Estabelecendo a importância da pesquisa e/ou \\
\cline { 2 - 3 } & Passo 2: Fazendo generalizações sobre o assunto e/ou \\
\cline { 2 - 2 } & Passo 3: Revisando itens de pesquisas anteriores \\
\hline \multirow{3}{*}{$\begin{array}{c}\text { Movimento 2 } \\
\text { Ocupar o nicho }\end{array}$} & Passo 1: Esboçando os objetivos e/ou \\
\cline { 2 - 2 } & Passo 2: Indicando a estrutura do artigo e/ou \\
\cline { 2 - 2 } & Passo 3: Descrevendo procedimentos metodológicos e/ou \\
\cline { 2 - 2 } & Passo 4: Vinculando o estudo a um projeto \\
\hline
\end{tabular}

Fonte: Elaboração dos autores

Quadro 3 - Organização retórica da introdução do artigo em Matemática

\begin{tabular}{|c|lr|}
\hline \multirow{2}{*}{$\begin{array}{c}\text { Movimento 1 } \\
\text { Estabelecer um território }\end{array}$} & Passo 1: Fazendo generalizações sobre o assunto & e/ou \\
\cline { 2 - 3 } & Passo 2: Revisando itens de pesquisas prévias & e/ou \\
\hline \multirow{2}{*}{$\begin{array}{c}\text { Movimento 2 } \\
\text { Ocupar o nicho }\end{array}$} & Passo 1: Esboçando os objetivos & e/ou \\
\cline { 2 - 3 } & Passo 2: Indicando a estrutura do artigo \\
\cline { 2 - 3 } & Passo 3: Descrevendo procedimentos metodológicos \\
\hline
\end{tabular}

Fonte: Elaboração dos autores

A partir das análises, percebemos que os autores das introduções da área de Letras distribuíram as informações na introdução do artigo a partir de estratégias mais diversificadas, mobilizando recorrentemente duas estratégias a mais do que os da área de Matemática, uma em cada movimento retórico. As estratégias peculiares das introduções de Letras indicam a atenção dessa área para a enunciação da importância da pesquisa, para a revisão de pesquisas prévias por meio de citações diretas e indiretas e para informação sobre o Programa ao qual o estudo está vinculado. Quanto às 
introduções de Matemática, além do leque mais reduzido de opções, destaca-se a realização mais objetiva e direta das estratégias retóricas.

A nossa hipótese para esse maior detalhamento das informações em Letras é a tradição mais interpretativa dos estudos das ciências humanas e sociais, cuja construção argumentativa se desenvolve de forma mais complexa, por oposição às ciências exatas e da saúde, em que se verifica uma tendência para a utilização de uma linguagem mais objetiva, resultando em textos mais sucintos. Essas peculiaridades apontam para os diferentes modos como os campos disciplinares compreendem e constroem os próprios objetos de estudo.

\section{Considerações finais}

A partir da análise do corpus, percebemos que dos onze passos dispostos por Swales (1990) no Modelo CARS, nove foram realizados, porém apenas cinco foram recorrentes nos textos, quais sejam: Estabelecendo a importância da pesquisa, Fazendo generalizações sobre o assunto, Revisando itens de pesquisas anteriores, Esboçando os objetivos e Indicando a estrutura do artigo. Isso nos parece muito positivo, uma vez que estamos diante de áreas disciplinares distintas e, apesar disso, encontramos a mobilização de informações semelhantes em ambas. Essa semelhança sugere que as estratégias retóricas foram selecionadas de modo que a seção introdutória possa cumprir seu objetivo, apresentando, em grande parte, os passos prototípicos esperados para a introdução de um artigo.

Em face desses resultados, pode-se depreender que as estratégias mobilizadas se configuram como constitutivas da seção de introdução do artigo científico, vista como o espaço indicado para se expor a relevância da pesquisa; inserir o tópico do estudo em um campo mais amplo (generalizações); brevemente revisar a literatura, apresentando quais autores contribuirão para o desenvolvimento do estudo; explicitar o objetivo da 
pesquisa; e orientar o leitor com uma apresentação panorâmica de como o texto estará organizado.

Além da confirmação de parte expressiva das estratégias constantes do modelo, tanto a pouca recorrência do Movimento 2 e a ausência de alguns passos, como a ocorrência de estratégias não previstas pelo Modelo CARS, conforme verificadas em ambas as áreas, faz ressaltar as qualidades de um modelo de análise que Swales (2009) caracteriza como "bom": sua maleabilidade e simplicidade, que lhe permitem dar conta de um universo maior de dados e situações de análise. É preciso relembrar, a propósito disso, que os passos, no Modelo CARS, são em sua maioria opcionais e alternativos, de modo que não precisam se realizar em sua totalidade para que o modelo seja válido.

No que concerne às especificidades, de modo geral, observamos que as estratégias retóricas mobilizadas nos textos de Letras e de Matemática não foram tão discrepantes, embora as introduções da área de Letras se caracterizem por uma maior extensão dos textos. Ainda assim, foi visto que os autores de Letras lançaram mão, em suas introduções, de algumas estratégias a mais do que os de Matemática, o que é percebido pela mobilização de mais de um passo simultâneo em cada movimento realizado. Cabe ainda observar que os textos da área de Matemática parecem priorizar o Movimento 3 (Ocupar o nicho), apresentando uma concentração de passos nesse movimento. Em Letras, também são contempladas mais informações que apresentam a importância do estudo e contextualizam a pesquisa, como a inclusão de dados sobre o Programa ao qual o trabalho está vinculado, presente em todos os exemplares do corpus.

Contudo, dada a limitação deste estudo à análise textual, não nos é possível afirmar se essa última estratégia caracteriza a área ou se se trata de atender a uma recomendação do professor-orientador. Estudos futuros, que incluam a análise de um corpus mais amplo, abrangendo mais instituições, bem como usando outros instrumentos metodológicos, poderiam lançar luzes sobre essa questão.

Por fim, esperamos que este estudo contribua com o campo de investigações da escrita acadêmica em duas direções principais: em primeiro lugar, por abordar o gênero artigo científico, sinalizando o potencial de aplicação do modelo $C A R S$ para a orientação de graduandos no processo de escrita apoiada em exemplares reais do gênero e não em manuais normativos que não levam em consideração as especificidades de cada área. Em 
segundo lugar, por se colocar ao lado de trabalhos que elegem textos de graduandos como objeto de estudo, oferecendo visibilidade a membros periféricos da comunidade acadêmica que ainda buscam construir sua voz e autoria ao se inserir na prática de escrita de artigos.

\section{Referências}

ARAÚJO, Antonia Dilamar. Lexical signalling: a study of unspecific-nouns in book reviews. 1996. 284 f. Tese (Doutorado em Linguística) - Universidade Federal de Santa Catarina, Florianópolis, 1996.

ASKEHAVE, Inger; SWALES, John M. Genre identification and communicative purpose: a problem and a possible solution. Applied Linguistics, v. 22, n. 2, p. 195-212, 2001.

BAWARSHI, Anis; REIFF, Mary J. Gênero: história, teoria, pesquisa, ensino. São Paulo: Parábola Editorial, 2013.

BAZERMAN, Charles. Gêneros textuais, tipificação e interação. 4 ed. São Paulo: Cortez, 2011.

BERNARDINO, Cibele G.; ABREU, Nícollas O. A seção de introdução em artigos acadêmicos experimentais da cultura disciplinar de psicologia: um estudo sociorretórico. Raído, v. 11, n. 27, p. 463-482, 2017.

BERNARDINO, Cibele G.; PACHECO, Jorge Tércio S. Uma análise sociorretórica de introduções em artigos originais da cultura disciplinar da área de nutrição. Fórum linguístico, Florianópolis, v. 14, n.1, p. 1749-1766, jan./mar. 2017.

BERNARDINO, Cibele G.; VALENTIM, Dawton L. O gênero artigo acadêmico e a cultura disciplinar da área do direito: as primícias de uma análise sociorretórica. RevLet: Revista Virtual de Letras, v. 8, n. 2, p. 122-141, 2016.

BEZERRA, Benedito G. A organização retórica de resenhas acadêmicas. Linguagem em (Dis)curso, Tubarão-SC, v. 3, n. 1, p. 37-68, jul./dez. 2002. 
BEZERRA, Benedito G. Gêneros introdutórios em livros acadêmicos. Tese (Doutorado em Linguística) - Programa de Pós-graduação em Letras, Universidade Federal de Pernambuco, Recife, 2006.

BEZERRA, Benedito G. Gêneros no contexto brasileiro: questões (meta)teóricas e conceituais. São Paulo: Parábola Editorial, 2017.

BEZERRA, Benedito G. Letramentos acadêmicos e construção da identidade: a produção do artigo científico por alunos de graduação. Linguagem em (Dis)curso, Tubarão-SC, v. 15, n. 1, p. 61-76, jan./abr. 2015.

BIASI-RODRIGUES, Bernardete; BEZERRA, Benedito G. Propósito comunicativo em análise de gêneros. Linguagem em (Dis)curso, Tubarão/SC, v. 12, n. 1, p. 231-249, jan./abr. 2012.

BIASI-RODRIGUES, Bernardete; HEMAIS, Bárbara; ARAÚJO, Júlio C. Análise de gêneros na abordagem de Swales: princípios teóricos e metodológicos. In: BIASI-RODRIGUES, B.; ARAÚJO, J. C.; SOUSA, S. C. T. (Orgs.). Gêneros textuais e comunidades discursivas: um diálogo com John Swales. Belo Horizonte: Autêntica, 2009. p. 17-31.

CONNOR, Ulla. Contrastive rhetoric: cross-cultural aspects of second-language writing. Cambridge: Cambridge University Press, 1996.

COTOS, Elena; HUFFMAN, Sarah; LINK, Stephanie. Furthering and applying move/step constructs: Technology-driven marshalling of Swalesian genre theory for EAP pedagogy. Journal of English for Academic Purposes, n. 19, 2015, 52-72.

FIGUEIREDO, Débora de C.; BONINI, Adair. Práticas discursivas e ensino do texto acadêmico: concepções de alunos de mestrado sobre a escrita. Linguagem em (Dis)curso - LemD, Tubarão, v. 6, n. 3, p. 413-446, set./dez. 2006.

FISCHER, Adriana; HOCHSPRUNG, Vitor. Prática de escrita na universidade: a perspectiva dos letramentos acadêmicos sobre produções dos estudantes de Letras. Miguilim, v. 6, p. 44-66, 2017. 
FLOREK, Cristiane S. Organização retórica do resumo acadêmico gráfico: um gênero acadêmico multimodal. Revista de Estudos da Linguagem, v. 25, n. 4, p. 2293-2327, out./dez. 2017.

GUSTAVII, Björn. Como escrever e ilustrar um artigo científico. São Paulo: Parábola Editorial, 2017.

HYLAND, Ken. Disciplinary discourses: social interactions em academic writing. Michigan Classics, 2004.

MACEDO, Tatiana S. de; PAGANO, Adriana S. Análise de citações em textos acadêmicos escritos. DELTA, v. 27, n. 2, p. 257-288, 2011.

MARCUSCHI, Luiz Antonio. Produção textual, análise de gêneros e compreensão. São Paulo: Parábola Editorial, 2008.

MILLER, Carolyn R. Gênero textual, agência e tecnologia. São Paulo: Parábola Editorial, 2012.

MOTTA-ROTH, Désirée. Rhetorical features and disciplinary cultures: a genre-based study of academic book reviews in linguistics, chemistry and conomics. 1995. Tese (Doutorado em linguística) - Universidade Federal de Santa Catarina, Florianópolis, 1995.

MOTTA-ROTH, Désirée; HENDGES, Gracilela R. Produção textual na universidade. São Paulo: Parábola Editorial, 2010.

OLIVEIRA, Eliane F. Letramentos acadêmicos: o gerenciamento de vozes em resenhas e artigos científicos produzidos por alunos universitários. 2015. 466 f. Tese (Doutorado em Linguística Aplicada) - Instituto de Estudos da Linguagem, Universidade Estadual de Campinas, Campinas, 2015.

OLIVEIRA, John Hélio P. Análise de gêneros em contextos específicos: organização retórica e construção de sentidos no resumo de comunicação para eventos acadêmicos. 2017. Dissertação (Mestrado em Ciências da Linguagem) - Universidade Católica de Pernambuco, Recife, 2017. 
PAIVA, Francisco Jeimes O. A construção de um modelo de análise do gênero Artigo Acadêmico Experimental (AAE): ensinando, negociando e compartilhando conhecimentos. Revista Práticas de Linguagem, v. 8, p. 285-300, 2019.

PEREIRA, Regina C. M.; BASÍLIO, Raquel; LEITÃO, Poliana D. V. Artigo científico: um gênero textual caleidoscópico. DELTA, v. 33, n. 3, p. 663-695, 2017.

RITTI-DIAS, F. G.; BEZERRA, B. G. Análise retórica de introduções de artigos científicos da área da saúde pública. Horizontes de Linguística Aplicada. v. 12, n. 1, p. 163-182, 2013. SILVEIRA, Maria Inez M. Análise de gênero textual: concepção sócio-retórica. Maceió: EDUFAL, 2005 .

SWALES, John M. Genre analysis: English in academic and research settings. Nova York: Cambridge University Press, 1990.

SWALES, John M. Research genres: exploration and applications. Cambridge: Cambridge University Press, 2004.

SWALES, John M. Research into the structure of introductions to journal articles and its application to the teaching of academic writing. In: WILLIAMS, Ray; SWALES, John M; KIRKMAN, John (ed.). Common ground: shared interests in ESP and communication studies. Oxford: Pergamon Press, 1984. p. 77-86.

SWALES, John M. Sobre modelos de análise. In: BIASI-RODRIGUES, Bernardete; ARAÚJO, Júlio César; SOUSA, Socorro Cláudia T. (Orgs). Gêneros textuais e comunidades discursivas: um diálogo com John Swales. Belo Horizonte: Autêntica, 2009.

Recebido em 03/06/2020.

Aprovado em 14/10/2020. 